\title{
Longitudinal study of the ionospheric response to the geomagnetic storm of 15 May 2005 and manifestation of TADs
}

\author{
S. Sharma ${ }^{1}$, P. Galav ${ }^{1}$, N. Dashora ${ }^{2}$, and R. Pandey ${ }^{1}$ \\ ${ }^{1}$ Department of Physics, M. L. S. University, Udaipur 313 001, India \\ ${ }^{2}$ National Atmospheric Research Laboratory, Gadanki 517 512, India
}

Received: 23 December 2010 - Revised: 28 March 2011 - Accepted: 17 May 2011 - Published: 17 June 2011

\begin{abstract}
Response of low latitude ionosphere to the geomagnetic storm of 15 May 2005 has been studied using total electron content (TEC) data, obtained from three GPS stations namely, Yibal, Udaipur and Kunming situated near the northern crest of equatorial ionization anomaly at different longitudes. Solar wind parameters, north-south component of the interplanetary magnetic field (IMF $B_{\mathrm{Z}}$ ) and $\mathrm{AE}$ index data have been used to infer the strength of the geomagnetic storm. A large value of eastward interplanetary electric field at 06:15 UT, during the time of maximum southward IMF $B_{\mathrm{Z}}$ has been used to infer the transmission of an eastward prompt penetration electric field (PPEF) which resulted in a peak in TEC at 07:45 UT due to the local uplift of plasma in the low latitudes near the anomaly crest over a wide range of longitudes. Wave-like modulations superposed over the second enhancement in TEC between 09:15 UT to 10:30 UT have been observed at all the three stations. The second enhancement in TEC along with the modulations of up to 5 TECU have been attributed to the combined effect of super plasma fountain and traveling atmospheric disturbances (TAD). Observed large enhancements in TEC are a cause of concern for satellite based navigation and ground positioning. Increased $\left[\mathrm{O} / \mathrm{N}_{2}\right]$ ratio between 09:15 UT to 10:15 UT when modulations in TEC have been also observed, confirms the presence of TADs over a wide range of longitudes.
\end{abstract}

Keywords. Ionosphere (Electric fields and currents; Ionosphere-magnetosphere interactions; Ionospheric disturbances)

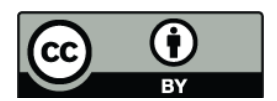

Correspondence to: R. Pandey

(pandey.rj@gmail.com)

\section{Introduction}

Studies of the geomagnetic storms and impacts thereof on Ionosphere-Thermosphere-Magnetosphere coupling processes are of great interest as such studies are covered under the ambit of space weather. Major geomagnetic storms are triggered by the earth directed coronal mass ejections (CMEs) from the sun when under the condition of a southward interplanetary magnetic field (IMF $B_{\mathrm{Z}}$ ), interaction between the solar wind and magnetosphere causes under shielding conditions and produces electric fields at the magnetospheric heights that may penetrate up to the equatorial latitudes. These fields are termed prompt penetration electric fields, PPEF (Nishida et al., 1966; Fejer et al., 1979; Fejer, 2002), which are eastward (westward) during the daytime (nighttime). It is generally believed that the PPEFs have rise and decay time of about $10-30 \mathrm{~min}$, and are short lived and may last for an hour or so (Gonzalez et al., 1979; Senior and Blanc, 1984; Spiro et al., 1988; Fejer et al., 1990; Fejer and Scherliess, 1997; Fejer et al., 2007). However in a recent study (Huang et al., 2005) it has been shown that the PPEF may sustain up to several hours.

The other interesting phenomenon that has been observed and reported in several studies during geomagnetic storms is the traveling atmospheric disturbances (TADs) (Crowley and McCrea, 1988; Prolss, 1997; Fuller-Rowell et al., 2002; Yizengaw et al., 2005; Bruinsma and Forbes, 2007; Dashora et al., 2009). The excessive and impulsive energy input at high latitudes during the storms may launch TADs that travel from high latitudes (Hines, 1960; Balthazor and Moffett, 1997) meridionally towards the equator with high speed. The TADs upwell the ionized plasma along the magnetic field lines (Kirchengast et al., 1996; Sastri et al., 2000) to higher altitudes where it survives for longer time due to lower recombination rates. Ionospheric manifestation of TADs is called the traveling ionospheric disturbances (TIDs).

Published by Copernicus Publications on behalf of the European Geosciences Union. 
In the last two decades, global positioning system (GPS) has emerged to be a very powerful tool for the satellite based navigation and ground positioning. The ionospheric parameter on which the GPS based navigation is critically dependent is the total electron content (TEC) between a satellite and the ground based receiver. Since the range errors in the GPS based positioning are directly proportional to the TEC, GPS based navigation may be seriously impaired by the severe space weather events. Thus, success of the GPS based navigation is intimately dependent on the state of the ionosphere as the TEC is known to vary drastically during various space weather events such as geomagnetic storms. Hence it becomes imperative to study the TEC variations during geomagnetic storms to establish and ensure efficacy of the GPS based navigation under all-weather conditions. Such studies become all the more relevant in the equatorial ionization anomaly (EIA) region where the largest TEC values and gradients thereof are known to exist. The added advantage of GPS based ionospheric studies is the broad spatial and temporal coverage, facilitated by the 32 satellites in near circular orbits at about $20200 \mathrm{~km}$ altitude.

Ionospheric response to each geomagnetic storm may be varied due to its time of occurrence, electrodynamical processes, chemical composition and neutral winds. Storm time changes in these can lead to positive (Zhao et al., 2005; Basu et al., 2007; Dashora et al., 2009) or negative (Buonsanto, 1999; Mendillo, 2006; Dashora and Pandey, 2007) ionospheric storms. And therefore ionospheric studies related to space weather disturbed conditions are required to characterize all aspects of ionospheric behavior under the different storm conditions.

Behavior of low latitude ionosphere during the geomagnetic storms results from changes in the electric field and thus the plasma electrodynamics. These electrodynamical and electrical changes propagate from polar to low latitudes, having wide range of their manifestations (Abdu, 1997; FullerRowell et al., 1997; Sastri et al., 2003).

Very few geomagnetic storms occurred during the declining phase of solar cycle 23, after the year 2004. Among these, the geomagnetic storms of May and August 2005 were quite significant from the point of view of their impact on the low latitude ionosphere. Of these two storms, the one of 15 May 2005 could be characterized by a large southward IMF $B_{\mathrm{Z}}$ and SYM-H values. The event was particularly significant due to quiet geomagnetic conditions that prevailed just before and after its occurrence. Hence its ionospheric effects could be gauged very accurately. Also it was associated with a shorter period of southward IMF $B_{\mathrm{z}}$, such that it became northward after about three hours. The aim of the present work is to investigate the longitudinal extent of the TADs in the daylight ionosphere, near the northern crest of EIA. For this purpose, we have investigated the response of low latitude ionosphere in terms of GPS derived TEC at three stations located within $55^{\circ} \mathrm{E}$ to $105^{\circ} \mathrm{E}$ longitudes along with the variations in the thermospheric $\left[\mathrm{O} / \mathrm{N}_{2}\right]$ ratio. This study would enable us to examine the behavior of ionosphere over a range of longitudes that lie in the local daytime around the northern crest of the EIA. This study is significant for the scientists working in the fields of magnetosphere and ionosphere and also for the system engineers and model developers as it reveals a positive ionospheric storm wherein, compared to a quiet day, the TEC increased by up to a factor of three in the region close to the crest of the EIA. Since such large variations in TEC have deleterious effects on the satellite based navigation and communication, study of the ionospheric response due to each geomagnetic storm at multiple locations acquire added importance.

\section{Data set}

Signals transmitted by GPS satellites at two different frequencies, $L_{1}=1575.42 \mathrm{MHz}$ and $L_{2}=1227.6 \mathrm{MHz}$ are received by the ground based receivers. Since ionosphere is a dispersive medium, passage of the signals through it introduces a phase difference between the two signals. By measuring this phase difference, the line of sight TEC, the slant TEC, between a satellite-receiver pair can be estimated. This slant TEC has certain errors; for ionospheric studies the errors due to the satellite and receiver biases are most important. These errors have to be removed during the post processing of the data. It is also customary to convert the slant TEC (STEC) into the vertical TEC (VTEC) at the ionospheric pierce point location through the formula (Ma and Maruyama, 2003).

$\mathrm{VTEC}=\mathrm{STEC} \times\left[1-\left(\frac{R_{\mathrm{E}} \cos \theta}{R_{\mathrm{E}} h_{\max }}\right)^{2}\right]^{1 / 2}$

Here $\theta$ is the elevation angle of the satellite, $R_{\mathrm{E}}$ is the radius of the Earth and $h_{\max }$ is the height of the ionospheric shell above the surface of the earth. For the present work a thin ionospheric shell at an altitude of $350 \mathrm{~km}$ has been assumed. Since conversion errors for lower satellite elevation angles are large, it is advisable to use a higher elevation angle cut off. We have used a cut off angle of $40^{\circ}$ for the present work. Data from three GPS stations has been used. The chosen stations lie in three different longitudes but have nearly same geographic (geomagnetic) latitudes around the northern crest of EIA. Of these three stations, the ones at Yibal (Oman), YIBL (Geog. Lat. 22.18 ${ }^{\circ}$ N, Geog. Long. $56.11^{\circ} \mathrm{E}$, Geomag. Lat. $15.8^{\circ} \mathrm{N}$ ) and Kunming (China), KUNM (Geog. Lat. $25.03^{\circ} \mathrm{N}$, Geog. Long. $102.79^{\circ} \mathrm{E}$, Geomag. Lat. $15.05^{\circ} \mathrm{N}$ ) are the IGS (International GNSS Service) stations. The third GPS is installed at Udaipur, India (Geog. Lat. $24.67^{\circ} \mathrm{N}$, Geog. Long. $74.69^{\circ} \mathrm{E}$, Geomag. Lat. $16.22^{\circ} \mathrm{N}$ ) and it lies between these two. The data from the IGS sites is available in public domain in the RINEX (Receiver INdependent EXchange) format. We have used indigenously developed programs (Sharma et al., 2011) for retrievals of TEC from the RINEX formatted data. 


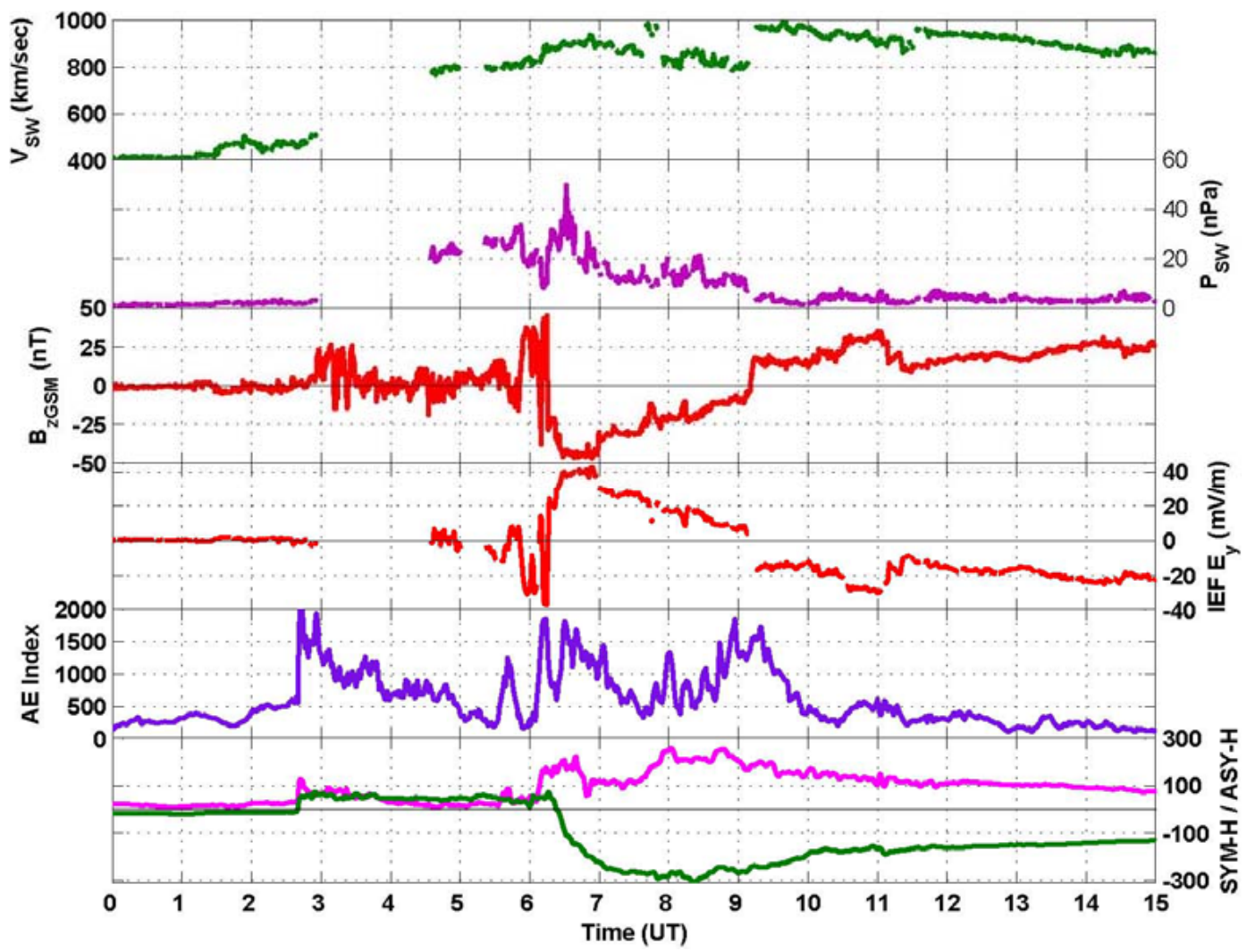

Fig. 1. The solar wind speed, ram pressure, IMF $B_{\mathrm{z}}$, zonal interplanetary electric field (IEF $E_{\mathrm{y}}$ ), AE index, SYM-H and ASY-H indices variations on 15 May 2005. A large eastward electric field after 06:15 UT is clearly seen. Three episodes of large AE index are also seen.

We have also made use of solar wind velocity $V_{\mathrm{SW}}$ and density to calculate the solar wind ram pressure $P_{\mathrm{SW}}$. $16 \mathrm{~s}$ averaged IMF $B_{\mathrm{Z}}$ data from the ACE satellite and the per minute data of the indices AE, SYM-H and ASY-H have been used. In order to study the storm time changes in thermospheric neutral composition, we have made use of the thermospheric $\mathrm{O} / \mathrm{N}_{2}$ ratio, measured by the global ultraviolet imager (GUVI) instrument, onboard NASA's TIMED satellite.

The east-west component of interplanetary electric field, IEF $E_{\mathrm{y}}$, has been calculated using the formula, IEF $E_{\mathrm{y}}=$ $-B_{\mathrm{Z}} \times V_{\mathrm{SW}}$.

\section{Results and discussion}

\subsection{Geomagnetic conditions, solar wind parameters and AE index variation}

In order to characterize the storm and to study effects thereof on the TEC, variations of solar wind velocity and pressure, IMF $B_{\mathrm{z}}$, IEF $E_{\mathrm{y}}, \mathrm{AE}, \mathrm{SYM}-\mathrm{H}$ and ASY-H indices have been plotted in Fig. 1 against the universal time, UT. For better comparison of IMF $B_{Z}$ and the ground based parameter SYM-H, the solar wind parameters and IMF $B_{\mathrm{Z}}$ have been shifted by about $45 \mathrm{~min}$ in time to account for the time taken by the solar wind in traveling from the location of the ACE satellite to the magnetosphere.

On 15 May the IMF $B_{\mathrm{Z}}$ suddenly increased at 05:30 UT and attained a maximum northwardly value of $\sim 40 \mathrm{nT}$. IMF $B_{\mathrm{Z}}$ remains at this level for about half an hour, till 06:00 UT. Thereafter the IMF $B_{\mathrm{Z}}$ sharply turned southward and attained its maximum value of about $-45 \mathrm{nT}$ at 06:30 UT. IMF $B_{\mathrm{Z}}$ remained at this value for about $35 \mathrm{~min}$ (till 07:00 UT) and then started to recover. The observed maximum solar wind velocity was $\sim 1000 \mathrm{~km} \mathrm{~s}^{-1}$ during the maximum southward value of IMF $B_{Z}$ on 15 May 2005. At around 09:00 UT the IMF $B_{\mathrm{Z}}$ crossed its zero level and remained northward until 11:00 UT. Concurrent with the southward turning of IMF $B_{\mathrm{Z}}$, an eastward IEF $E_{\mathrm{y}}$ was produced that attained its maximum value of about $40 \mathrm{mV} \mathrm{m}^{-1}$ at around 06:30 UT. Thereafter, as the IMF $B_{\mathrm{Z}}$ tends to recover, the IEF $E_{\mathrm{y}}$ starts decreasing and at around 09:00 UT it becomes westward. Thus the main phase of the storm on 15 May remains for about one hour, till 07:00 UT. Auroral activity and the energy deposition at the high latitudes on 15 May could be inferred from the AE index given in Fig. 1. Unlike the solar wind parameters, the $\mathrm{AE}$ index exhibits three peaks on 15 May centered around 02:45 UT, 06:10 UT and 09:00 UT, respectively, each with a peak value of about $2000 \mathrm{nT}$. These three peaks in AE index, 

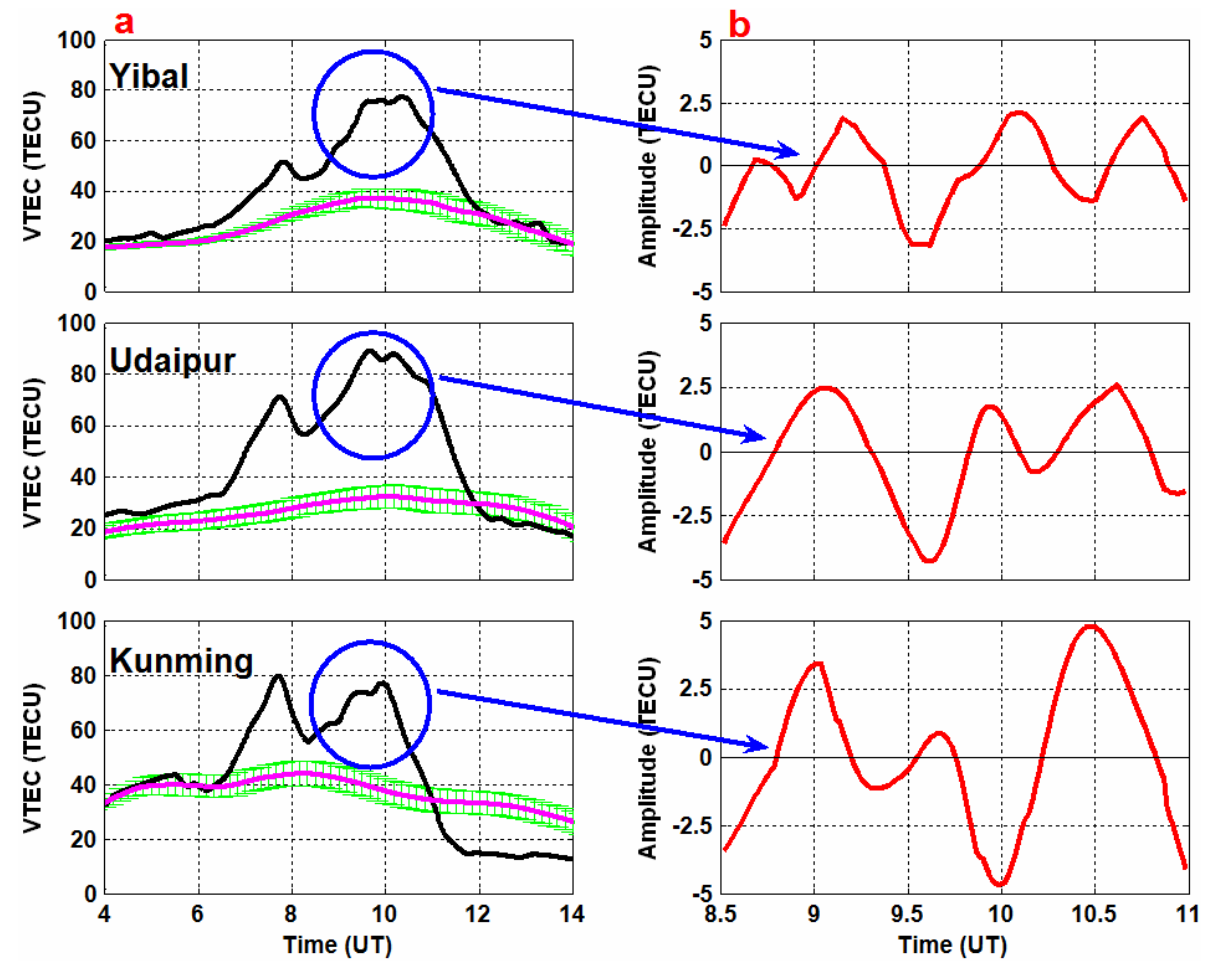

Fig. 2. (a) Variation of averaged storm day VTEC (in black) computed using data from satellites having elevation angle greater than $40^{\circ}$ at Yibal, Udaipur and Kunming. The quiet day mean VTEC (in magenta) is also plotted with $2 \sigma$ variations in green. Significant modulations of VTEC around the second enhancement (enclosed by an ellipse) are clearly observable and have been attributed to TADs. (b) Amplitude and period of TEC modulations observed from 08:30 UT to 11:00 UT. These have been computed by fitting a polynomial to the VTEC variation of Fig. $2 \mathrm{a}$ and differencing it from the actual VTEC variation at each station. Maximum amplitude of \pm 5 TECU is obtained.

on 15 May, may be taken to be indicative of a large deposition of energy at high latitudes. From the last panel of Fig. 1 which gives the variation of SYM-H index, it is apparent that the storm of 15 May 2005 was a major storm as its largest value is seen to be around $-305 \mathrm{nT}$.

\subsection{Longitudinal variation of VTEC}

We have studied the ionospheric variation during the disturbed space weather conditions arising from the geomagnetic storm of 15 May 2005, in terms of GPS derived TEC at three different longitudes, covering $55^{\circ} \mathrm{E}$ to $105^{\circ} \mathrm{E}$. These three stations are situated around $15^{\circ} \mathrm{N}$ Geomagnetic Latitude, near the northern crest of EIA. To illustrate the behavior of ionosphere on the storm day, TEC data from satellites whose elevation angle was higher than $40^{\circ}$ at each station has been used and shown (in black) in Fig. 2a, for UT hours 04:00 to 14:00. For comparison of storm day VTEC, the mean VTEC (in magenta), computed from the data of geomagnetic quiet days of May 2005, has also been plotted for each station. The day to day variability of VTEC has been shown by the $2 \sigma$ variation (in green) over the mean VTEC. It can be seen from Fig. 2a that the mean VTEC at Yibal maximizes at around 10:15 UT with a value of about 40 TECU.
For Udaipur, the maximum value of the mean VTEC is about 35 TECU, occurring at 09:30 UT. However, the mean VTEC for Kunming shows a maximum around 08:00 UT with a value of about 45 TECU. Therefore, the approximate local time of maximization of mean VTEC for Yibal is $\sim 14: 00 \mathrm{LT}$ (UT $+4 \mathrm{~h}$ ) and for Udaipur it is $\sim 15: 00 \mathrm{LT}$ $(\mathrm{UT}+5 \mathrm{~h})$. Whereas for Kunming, the local time of maximization of mean VTEC is $\sim 15: 00 \mathrm{LT}(\mathrm{UT}+7 \mathrm{~h}$ ). Storm day variation of VTEC at the three stations show almost common features, namely, two distinct enhancements in VTEC are observed. The first enhancement, which stands out as a single peak at all the stations, is seen at the same time, around 07:50 UT. The second enhancement is superposed by wave like structures, and is observed between 09:15 to 10:30 UT at different stations.

Observation of first peak in VTEC at almost same time at all the three stations (with nearly same magnetic latitude) points to a common mechanism for its formation. It can be seen from Fig. 1, the storm main phase commenced at around 06:15 UT. This is the time when under shielding conditions developed and the interplanetary electric field penetrated to the low latitudes as an eastward PPEF. This PPEF significantly modified the existing electric fields and plasma dynamics in low and equatorial latitudes (Dashora et al., 2009). 
In the local day time sector, this eastward PPEF enhances the vertical $\boldsymbol{E} \times \boldsymbol{B}$ drift; resultantly low altitude plasma moves up and survives for comparatively longer time due to lower recombination rate at higher altitudes. This gives rise to a positive ionospheric storm (e.g., Buonsanto, 1999) whereby the TEC is also increased. As is expected, local uplifting of plasma and its re-distribution due to the eastward PPEF would have a certain time constant and has been observed by others also (Tsurtani et al., 2004; Bagiya et al., 2009). Therefore the first peak in VTEC occurs nearly after $1 \mathrm{~h} 45 \mathrm{~min}$ of the southward turning of the IMF $B_{\mathrm{z}}$. This result also implies that the daytime PPEF penetrates near simultaneously over a wide longitude zone. Compared to the second peak in VTEC, the amplitude of the first peak is seen to be increasing progressively from Yibal to Kunming. This is due to the local time dependence of development of EIA crest as seen in VTEC. While the time of first peak in VTEC nearly coincides with its normal peaking time at Kunming, at Yibal it is more than two hours earlier than its normal time of peaking. Thus, the first peak at Kuming is expected to be more pronounced than at Udaipur and Yibal.

After attaining the first peak around 07:50 UT, the VTEC is seen to decrease and tends to attain its normal value. This happens because the PPEF are short-lived. At around 08:15 UT, the VTEC is again seen to increase. Unlike the first peak, the rise in VTEC culminating in the second enhancement is seen to be a combination of multiple peaks with varying modulations. These modulations in VTEC are visible at all the three stations, between 09:15 UT to 10:30 UT. In our earlier study (Dashora et al., 2009) related to the same storm for the Indian longitude sector, we have shown that the second broad enhancement in the VTEC could be largely attributed to the super plasma fountain effect arising due to the eastward PPEF at 06:15 UT. This inference is based on the fact that the time of penetration of eastward PPEF nearly coincides with the time of maximization of the equatorial electrojet on a normal day which, for the longitudes under consideration, is about 11:00 LT. Thus the occurrence of PPEF at 06:15 UT resulted in the abnormally enhanced equatorial electroject at the time of its normal peaking. Hence the plasma fountain due to vertical $\boldsymbol{E} \times \boldsymbol{B}$ drift increased manifold and resulted in a super plasma fountain for the Indian longitudes. Whereas for Yibal the time of the occurance of PPEF (06:15 UT) corresponded to the local time 10:00 LT, that is, more than an hour earlier compared to the normal time of peaking of the equatorial electrojet. On the other hand, the local time of PPEF for Kunming was about two hours past the normal peaking time of equatorial electrojet. This probably explains the differences in the amplitude of the second enhancement at the three stations. Not only that a large range of longitudes could have drastic variations in VTEC following the storms, there is local time dependence also, as has been discussed above. This is also borne out by the fact that the VTEC variations at Udaipur at the time of the two enhancements are the largest, being 45 TECU and 55 TECU, respectively which are almost three times their normal values whereas for the other two stations such enhancements are nearly double.

Such large departures in averaged VTEC on the storm day from its corresponding values on the quiet day are a cause of grave concern for the system engineers working for satellite based navigation and communications. Since a change of 1 TECU corresponds to a range error of $0.16 \mathrm{~m}$, extremely large errors due to such variations in TEC during the storms are a serious threat to satellite based ground positioning and navigation.

In order to find out the amplitude and period of the modulations, VTEC around the second hump was fitted with an appropriate polynomial and its difference from the fitted curve was computed. The difference curves are shown in Fig. $2 b$. Wave like pattern is clearly seen in Fig. $2 b$ at all the three stations. The peak-to-peak amplitude of the modulations is within 5 TECU with an average period between $45-55 \mathrm{~min}$. The wave type modulations, superposed on the second enhancement in VTEC may be attributed to the TADs. This is justified in view of their observed periods that fall within the acceptable range of $0.5 \mathrm{~h}$ to $1.8 \mathrm{~h}$, as given by Ding et al. (2007). In our earlier work (Dashora et al., 2009) concerning the same storm, we had estimated the phase speeds of these wave like modulations to be around $485 \mathrm{~m} \mathrm{~s}^{-1}$, which is also consistent with the results of Ding et al. (2007) who report phase speeds in the range $300-1000 \mathrm{~m} \mathrm{~s}^{-1}$. The TADs have been shown to modulate the ionospheric density by up to $25 \%$ (Bruinsma and Forbes, 2007) even at low and equatorial latitudes. Hence assigning the observed modulations in VTEC to the TADs is justified. The source for the generation of these TADs could be found from Fig. 1, in terms of large enhancements in AE index, which are seen to be occurring in steps around 03:00, 07:00 and 09:00 UT, respectively. Of these AE enhancements, the one occurring between 06:0007:00 UT seems to be more plausible and responsible source for the generation of the observed signatures of TADs in VTEC. This inference has been reached based on the phase speed and time of occurrence of the observed TADs. Since the signatures of the TADs in VTEC have been observed over a longitude band of $50^{\circ}$, these results imply that the geomagnetic storms may result in the generation of TADs which could be observed over a much wider range of longitudes.

\subsection{Variation of thermospheric $\left[\mathrm{O} / \mathrm{N}_{2}\right]$ ratio}

It is widely believed (e.g., Tsugawa et al., 2006; Immel et al., 2001) that the storm induced meridional winds result in changes in chemical composition signified by thermospheric $\left[\mathrm{O} / \mathrm{N}_{2}\right]$ ratio. In order to confirm our inferences regarding TADs, we have looked for data from the GUVI on board the TIMED satellite which provides the ratio in a latitudelongitude grid of $1.75^{\circ} \times 1.75^{\circ}$. As the satellite passes over a longitude at nearly same UT hours on consecutive days, it provides for an easy comparison of the event day variations 

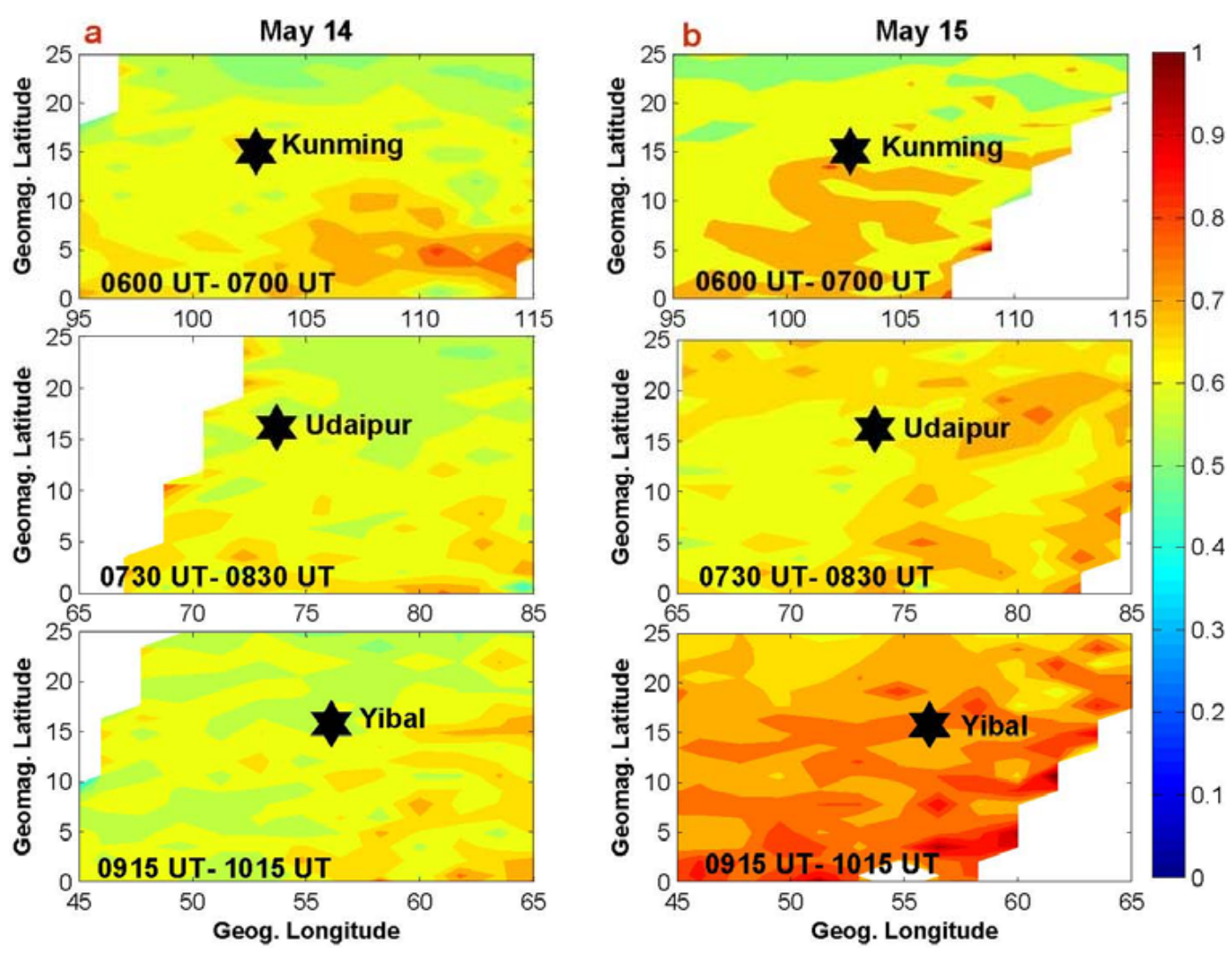

Fig. 3. Variation of $\left[\mathrm{O} / \mathrm{N}_{2}\right]$ on 14 May, an international geomagnetic quiet day (panel a) and on 15 May, the storm day (panel b) over a wide range of (magnetic) latitudes and longitudes. The UT hours shown in each panel correspond to the passage time of a satellite over the longitudes of the abscissa. The chosen GPS stations have been marked as a star in each panel. Large enhancements in [O/ $\left.\mathrm{N}_{2}\right]$ ratio on 15 May for longitude belt $45^{\circ}-65^{\circ} \mathrm{E}$ (bottom right panel) corresponding to the period 09:15 UT to 10:15 UT are clearly seen.

with that on a nearest quiet day. Further, since the satellite passes over different longitudes at different hours, a time history of the composition variations on a given day could be inferred. Figure $3 a$ and $b$ gives the variations of $\left[\mathrm{O} / \mathrm{N}_{2}\right]$ on 14 May (an international geomagnetic quiet day) and on 15 May (the storm day) over a wide range of (magnetic) latitudes and longitudes. It may be remarked here that with the passage of time, the consecutive satellite pass had been shifting towards the lower longitudes. The UT hours shown in each panel correspond to the passage time of a satellite over the longitudes of the abscissa. We have selected the longitude ranges in such a way that these cover $\pm 10^{\circ}$ longitude belt around the chosen GPS station, marked as a star in each panel of Fig. 3. The top panels of Fig. 3 show compositional ratios in the longitude belt $95^{\circ}-115^{\circ} \mathrm{E}$ whereas the middle and lower panels cover the longitude belts $65^{\circ}-85^{\circ} \mathrm{E}$ and $45^{\circ}-65^{\circ} \mathrm{E}$, respectively.

Comparison of panels for the period 06:00 UT-07:00 UT do not reveal significant changes due to the storm on 15 May. This is because the PPEF had just penetrated and the storm effects are not expected to be observed so soon. The middle panels for the time period 07:30 UT-08:30 UT reveal observable moderate changes in thermospheric composition over a wide latitude-longitude range on the storm day. Comparison of bottom panels shows remarkable enhancements in the thermospheric $\left[\mathrm{O} / \mathrm{N}_{2}\right]$ ratio on 15 May with respect to those on the quiet day. Increased $\left[\mathrm{O} / \mathrm{N}_{2}\right]$ ratio is indicative of the presence of strong equatorward meridional winds. It is worth mentioning here that the period of satellite pass for the bottom panels of Fig. $3 b$ coincides with that of the second enhancement in VTEC, as shown in Fig. 2 for 15 May. Thus it could be concluded that the modulations in VTEC seen around 09:30-10:30 $\mathrm{h}$ at all the stations are due to the TADs.

\section{Conclusions}

Variation of GPS derived total electron content have been used to study the effect of geomagnetic storm of 15 May 2005 on the ionosphere at three widely separated longitudes, but having same geomagnetic latitude. The main highlights of the present study are as follows:

1. Temporal variations of TEC due to a daytime geomagnetic storm at the three longitudes could be characterized by two distinct enhancements, The first of which 
has been attributed to the local uplift of ionospheric plasma due to the PPEF.

2. The second enhancement could be characterized by a broad maximum occurring between 09:15 UT and 10:30 UT that was superposed by wave-like modulations, whose peak-to-peak amplitude was within 5 TECU. These modulations have been inferred as the signature of the TADs whose period has been observed to range between $45-55 \mathrm{~min}$.

3. Vastly increased thermospheric $\left[\mathrm{O} / \mathrm{N}_{2}\right]$ ratio over a wide range of longitudes in the low latitudes (bottom panel of Fig. 3b), during the period when modulations in TEC were also observed, has been inferred to be due to upwelling by equatorward neutral winds.

Acknowledgements. This work is partially supported through grants from the University Grants Commission, New Delhi under SAP (DSA) scheme and Indian Space Research Organization, Bengaluru under the RESPOND program. One of the authors (SS) is thankful to UGC for the award of UGC-NET-SRF. For the present work, relevant data was downloaded from the following sites: ftp://garner.ucsd.edu/ (IGS GPS receiver data), http: //www.srl.caltech.edu/ACE/ASC/ (Solar wind parameters and IMF $B_{\mathrm{Z}}$ from ACE satellite), ftp://ftp.unibe.ch/aiub/CODE/ (Bias errors in GPS observables) and http://wdc.kugi.kyoto-u.ac.jp/ (SYM-H, ASY-H and AE indices). The GUVI data used here are provided through support from the NASA MO\&DA program. The GUVI instrument was designed and built by The Aerospace Corporation and The Johns Hopkins University. The Principal Investigator is Andrew B. Christensen and the Chief Scientist and co-PI is Larry J. Paxton.

Topical Editor K. Kauristie thanks E. Yizengaw and another anonymous referee for their help in evaluating this paper.

\section{References}

Abdu, M. A.: Major phenomena of the equatorial ionospherethermosphere system under disturbed conditions, J. Atmos. Solor-Terr. Phys., 59(13), 1505-1519, 1997.

Bagiya, Mala S., Joshi, H. P., Iyer, K. N., Aggarwal, M., Ravindran, S., and Pathan, B. M.: TEC variations during low solar activity period (2005-2007) near the Equatorial Ionospheric Anomaly Crest region in India, Ann. Geophys., 27, 1047-1057, doi:10.5194/angeo-27-1047-2009, 2009.

Balthazor, R. L. and Moffett, R. J.: A study of atmospheric gravity waves and travelling ionospheric disturbances at equatorial latitudes, Ann. Geophys., 15, 1048-1056, doi:10.1007/s00585997-1048-4, 1997.

Basu, S., Basu, Su., Rich, F. J., Groves, K. M., MacKenzie, E., Coker, C., Sahai, Y., Fagundes, P. R., and Becker-Guedes, F.: Response of the equatorial ionosphere at dusk to penetration electric fields during intense magnetic storms, J. Geophys. Res., 112, A08308, doi:10.1029/2006JA012192, 2007.

Bruinsma, S. L. and Forbes, J. M.: Global observation of traveling atmospheric disturbances (TADs) in the thermosphere, Geophys. Res. Lett., 34, L14103, doi:10.1029/2007GL030243, 2007.
Buonsanto, M. J.: Ionospheric storms: A review, Space Sci. Rev., 88, 563-601, 1999.

Crowley, G. and McCrea, I. W.: A synoptic study of TIDs observed in the UK during the first WAGS campaign, October 10-18, 1985, Radio Sci., 23, 905-917, doi:10.1029/RS023i006p00905, 1988.

Dashora, N. and Pandey, R.: Variations in total electron content near the crest of the equatorial ionization anomaly during the November 2004 geomagnetic storm, Earth Planets Space, 59, 127-131, 2007.

Dashora, N., Sharma, S., Dabas, R. S., Alex, S., and Pandey, R.: Large enhancements in low latitude total electron content during 15 May 2005 geomagnetic storm in Indian zone, Ann. Geophys., 27, 1803-1820, doi:10.5194/angeo-27-1803-2009, 2009.

Ding, F., Wan, W., Ning, B., and Wang, M.: Large-scale traveling ionospheric disturbances observed by GPS total electron content during the magnetic storm of 29-30 October 2003, J. Geophys. Res., 112, A0639, doi:10.1029/2006JA012013, 2007.

Fejer, B. G.: Low latitude storm time electrodynamics, J. Atmos. Solar-Terr. Phys., 64, 1401-1408, 2002.

Fejer, B. G. and Scherliess, L.: Empirical models of storm time equatorial electric fields, J. Geophys. Res., 102, 24047-24056, 1997.

Fejer, B. G., Gonzales, C. A., Farley, D. T., Kelley, M. C., and Woodman, R. F.: Equatorial electric fields during magnetically disturbed periods: 1. Effect of the interplanetary magnetic field, J. Geophys. Res., 84, 5797-5802, 1979.

Fejer, B. G., Spiro, R. W., Wold, R. A., and Foster, J. C.: Latitudinal variations of penetration electric fields during magnetically disturbed periods: 1986 SUNDIAL observations and model results, Ann. Geophys., 8, 441-454, 1990.

Fejer, B. G., Jensen, J. W., Kikuchi, T., Abdu, M. A., and Chau, J. L.: Equatorial Ionospheric Electric Fields During the November 2004 magnetic Storm, J. Geophys. Res., 112, A10304, doi:10.1029/2007JA012376, 2007.

Fuller-Rowell, T. J., Codrescu, M. V., Fejer, B. G., Borer, W., Marcos, F., and Anderson, D. N.: Dynamics of the low-latitude thermosphere: Quiet and disturbed conditions, J. Atmos. Solar Terr. Phys., 59(13), 1533-1540, 1997.

Fuller-Rowell, T. J., Millward, G. H., Richmond, A. D., and Codrescu, M. V.: Storm-time changes in the upper atmosphere at low latitudes, J. Atmos. Solar Terr. Phys., 64, 1383-1391, doi:10.1016/S1364-6826(02)00101-3, 2002.

Gonzalez, C. A., Kelley, M. C., Fejer, B. G., Vickrey, J. F., and Woodman, R. F.: Equatorial Electric Fields during magnetically disturbed conditions 2 . Implications of simultaneous auroral and equatorial measurements, J. Geophys. Res., 84, 5803 5812, 1979.

Hines, C. O.: Internal Atmospheric Gravity Waves at ionospheric heights, Can. J. Phys., 38, 1441-1481, 1960.

Huang, C. S., Foster, J. C., and Kelley, M. C.: Long-duration penetration of the interplanetary electric field to the low-latitude ionosphere during the main phase of magnetic storms. J. Geophys. Res., 110, A11309, doi:10.1029/2005JA011202, 2005.

Immel, T. J., Crowley, G., Craven, J. D., and Roble, R. G.: Dayside enhancements of thermospheric $\mathrm{O} / \mathrm{N}_{2}$ following magnetic storm onset, J. Geophys. Res., 106(A8), 15471-15488, 2001.

Kirchengast, G., Hocke, K., and Schlegel, K.: The gravity wave TID relationship: Insight via theoretical model EISCAT data 
comparison, J. Atmos. Terr. Phys., 58, 233-243, 1996.

Ma, G. and Maruyama, T.: Derivation of TEC and estimation of instrumental biases from GEONET in Japan, Ann. Geophys., 21, 2083-2093, doi:10.5194/angeo-21-2083-2003, 2003.

Mendillo, M.: Storms in the ionosphere: Patterns and processes for total electron content, Rev. Geophys., 44, RG4001, doi:10.1029/2005RG000193, 2006.

Nishida, A., Iwasaki, T., and Nagata, T.: The origin of fuctuations in the equatorial electrojet: a new type of geomagnetic variation, Ann. Geophys., 22, 478-484, 1966.

Prolss, G. W.: Magnetic storm perturbations of the upper atmosphere, in: Magnetic Storms, Geophys. Monogr. Ser., vol. 98, edited by: Tsurutani, B. T., Gonzalez, W. D., Kamide, Y., and Arballo, J. K., pp. 227-241, AGU, Washington, D.C., 1997.

Sastri, J. H., Jyoti, N., Somayajulu, V. V., Chandra, H., and Devasia, C. V.: Ionospheric storm of early November 1993 in the Indian equatorial region, J. Geophys. Res., 105, 18443-18455, 2000.

Sastri, J. H., Kamide, Y., and Yumoto, K.: Signatures for magnetospheric substorms in the geomagnetic field of dayside equatorial region: Origin of the ionospheric component, J. Geophys. Res., 108(A10), 1375, doi:10.1029/2003JA009962, 2003.

Senior, C. and Blanc, M.: On the control of magnetospheric convection by the spatial distribution of ionospheric conductivities, J. Geophys. Res., 89, 261-284, 1984.
Sharma, S., Dashora, N., Galav, P., and Pandey, R.: Cycle slip detection, correction and phase levelling of RINEX formatted GPS observables, Current Science, 100(2), 205-212, 2011.

Spiro, R. W., Wolf, R. A., and Fejer, B. G.: Penetration of highlatitude electric fields effects to low latitudes during SUNDIAL 1984, Ann. Geophys., 6, 39-49, 1988.

Tsugawa, T., Sadakane, T., Sato, J., Otsuka, Y., Ogawa, T., Shiokawa, K., and Saito, A.: Summer-winter hemispheric asymmetry of sudden increase in ionospheric total electron content induced by solar flares: A role of O/N2 ratio, J. Geophys. Res., 111, A11316, doi:10.1029/2006JA011951, 2006.

Tsurutani, B., Mannucci, A., Iijima, B., Abdu, M. A., Sobral, J. H. A., Humberto, A., Gonzalez, W., Guarnieri, F., Tsuda, T., Saito, A., Yumoto, K., Fejer, B. Fuller-Rowell, T .J., Kozyra, J., Foster, J. C., Coster, A., and Vasyliunas, V. M.: Global Dayside Ionospheric Uplift And Enhancement Associated With Interplanetary Electric Field, J. Geophys. Res., 109, A08302, doi:10.1029/2003JA010342, 2004.

Yizengaw, E., Dyson, P. L., Essex, E. A., and Moldwin, M. B.: Ionosphere dynamics over the Southern Hemisphere during the 31 March 2001 severe magnetic storm using multiinstrument measurement data, Ann. Geophys., 23, 707-721, doi:10.5194/angeo-23-707-2005, 2005.

Zhao, B., Wan, W., and Liu, L.: Responses of equatorial anomaly to the October-November 2003 superstorms, Ann. Geophys., 23, 693-706, doi:10.5194/angeo-23-693-2005, 2005. 